Portland State University

PDXScholar

Mechanical and Materials Engineering Faculty

Publications and Presentations

$10-2007$

\title{
The Urban Heat Island Mitigation Impact Screening Tool (MIST)
}

David J. Sailor

Portland State University

Nikolaas Dietsch

U.S. Environmental Protection Agency

Follow this and additional works at: https://pdxscholar.library.pdx.edu/mengin_fac

Part of the Climate Commons, and the Materials Science and Engineering Commons

Let us know how access to this document benefits you.

\section{Citation Details}

Sailor, D.J. and Dietsch, N., 2007 "The urban heat island mitigation impact screening tool (MIST)", Environmental Modelling and Software, 22, 1529-1541.

This Article is brought to you for free and open access. It has been accepted for inclusion in Mechanical and Materials Engineering Faculty Publications and Presentations by an authorized administrator of PDXScholar. Please contact us if we can make this document more accessible: pdxscholar@pdx.edu. 


\title{
The urban heat island Mitigation Impact Screening Tool (MIST)
}

\author{
David J. Sailor $^{\mathrm{a}, *}$, Nikolaas Dietsch ${ }^{\mathrm{b}}$ \\ ${ }^{\text {a }}$ Portland State University, Mechanical and Materials Engineering, PO Box 751-ME, Portland, OR 97207, USA \\ ${ }^{\mathrm{b}}$ U.S. Environmental Protection Agency, State and Local Branch, Washington DC, USA
}

Received 27 October 2005; received in revised form 25 May 2006; accepted 25 November 2006

Available online 5 February 2007

\begin{abstract}
A web-based software tool has been developed to assist urban planners and air quality management officials in assessing the potential of urban heat island mitigation strategies to affect the urban climate, air quality, and energy consumption within their cities. The user of the tool can select from over 170 US cities for which to conduct the analysis, and can specify city-wide changes in surface reflectivity and/or vegetative cover. The Mitigation Impact Screening Tool (MIST) then extrapolates results from a suite of simulations for 20 cities to estimate air temperature changes associated with the specified changes in surface characteristics for the selected city. Alternatively the user can simply define a nominal air temperature reduction that they hope to achieve with an unspecified mitigation scenario. These air temperature changes are then input to energy and ozone models to estimate the impact that the mitigation action may have on the selected city. The results presented by MIST include a high degree of uncertainty and are intended only as a first-order estimate that urban planners can use to assess the viability of heat island mitigation strategies for their cities. As appropriate, MIST analyses should be supplemented by more detailed modeling.
\end{abstract}

(C) 2006 Elsevier Ltd. All rights reserved.

Keywords: Air quality; Urban heat islands; Atmospheric modeling; Urban climate; Albedo; Urban forestry

\section{Background}

Cities are often warmer than their unbuilt surroundings a phenomenon referred to as the urban heat island (Landsberg, 1981; Oke, 1982). This phenomenon is governed in large part by significant differences between the energy budgets of cities and the countryside. A key driver of these energy budgets is the input of short wave solar energy at the surface of the earth. Many urban surfaces such as roadways and roofs have relatively low reflectivity to solar radiation (low albedo). While some of the radiation reflected from these surfaces leaves the urban environment much of it is intercepted and partially absorbed by other urban surfaces. As a result cities tend to have lower effective albedos than their surroundings. Of the solar energy absorbed by the urban surface some are convected away as sensible heat flux. The sensible heat flux

\footnotetext{
* Corresponding author. Tel.: +1 5037254265 .

E-mail address: sailor@cecs.pdx.edu (D.J. Sailor).
}

depends on the temperature difference between the surface and the air and in a complex manner on the wind profile, vertical mixing characteristics above the urban surface, and wind channeling effects of the city. Surfaces also lose heat through evaporation and transpiration processes that convert water from liquid to vapor phase. The resulting latent heat flux depends on the moisture availability of the substrate as well as the underlying humidity in the air near the surface. In contrast to the natural landscape cities tend to have little vegetation and due to a large fractional cover of impervious surfaces there also tends to be less surface moisture in urban areas (Oke, 1982; Owen et al., 1998). Surfaces also lose and gain heat through long wave radiative exchange with the environment. The amount of long wave radiative flux emitted by a surface is proportional to its emissivity and the fourth power of its temperature. The amount of long wave radiation received by a surface depends upon the temperatures and emissivities of surfaces in its surroundings. As is the case with short wave radiation, the urban geometry complicates long wave radiative exchange, tending to trap heat in the urban environment. 
Another unique component of the urban energy balance is the presence of waste heat that is emitted from a range of human activities - automobiles, air conditioning equipment, industrial facilities, and a variety of other sources, including human metabolism.

The result of the complex urban surface energy balance is that cities tend to be warmer than their rural surroundings. This "urban heat island" (UHI) is typically largest in winter and during the evening hours (Oke, 1981; Travis et al., 1987; Yoshikado et al., 1996; Morris and Simmonds, 2001). Nevertheless, the summertime UHI is of particular importance due to the consequences for urban air quality, air conditioning energy consumption, and heat related illness and mortality (Tarleton and Katz, 1995; Santamouris et al., 1999; Bornstein and Lin, 2000; Nielsen-Gammon, 2000; Lemonsu and Masson, 2002).

Mitigation strategies have been proposed to alleviate the negative effects of the summertime UHI (Rosenfeld et al., 1995; Estes, 2000; Akbari et al., 2001; Sailor et al., 2002). In particular these strategies take advantage of insights gained from study of the urban energy balance. Specifically, they seek to reduce the solar radiation absorbed by the surface or increase the latent heat flux away from the surface. The physical implementation of these strategies involves use of highly reflective (high albedo) roofing and paving materials, and extensive planting of urban vegetation. For example, high-albedo alternatives such as white elastomeric coatings can increase the albedo of typical commercial roofs from approximately $10 \%$ to nearly $70 \%$ (Rosenfeld et al., 1995). In detailed analyses of surfaces that comprise the urban fabric (Bretz et al., 1998) noted that there is significant potential in the US to increase pavement and rooftop albedos. For example, it is estimated that the surface of Sacramento, California is composed of $20 \%$ dark rooftops and $10 \%$ dark pavement. Bretz et al. (1998) suggests that the albedo of Sacramento could be increased by 0.18 using readily available materials. Similar analyses have been conducted to explore the potential urban climate impacts of increasing urban vegetation and planting shade trees (e.g., Sailor, 1998; Akbari, 2002). The impacts that shade trees or high-albedo rooftops have on individual buildings can be (1) estimated using building energy simulation software or (2) estimated through the direct monitoring of building energy consumption before and after modification of the building envelope (e.g., before and after re-roofing with a high-albedo alternative). Mitigation strategies, however, may also have a city-wide impact associated with the combined effect of many modified surfaces. For example, a vegetated rooftop (ecoroof) installed on one building can reduce the surface temperature of that building, and in turn, cool the adjacent air that influences the thermal environment of the entire city. In order to project the potential magnitude of this indirect atmospheric effect of mitigation strategies it is necessary to use regional (or mesoscale) atmospheric models. The atmospheric effect of mitigation strategies can, in turn, affect ambient air quality, human health, and city-scale energy consumption. These effects can be estimated using atmospheric model output to drive corresponding end point impact models (Sailor et al., 2002). While the atmospheric models used in such studies typically have spatial resolutions on the order-of $1-10 \mathrm{~km}$, more detailed models that attempt to parameterize the effects of individual urban canyons are becoming increasingly common (Herbert et al., 1998; Kusaka and Kimura, 2004). When linked with tools to assess the spatial distribution of urban surface characteristics (e.g., Feingersh et al., 2007), these models can provide crucial input to urban planning and public policy decisions. In past studies UHI mitigation analysis has been resource intensive, carried out independently for each city of interest, and repeated for a variety of representative atmospheric conditions in order to develop a good understanding of the potential costs and benefits of such strategies over time (e.g., cooling the urban climate generally saves energy in summer, but can increase energy consumption for heating in winter).

\section{Motivation}

As discussed above, research conducted to date suggests that albedo and vegetation strategies can reduce peak summertime urban air temperatures with concomitant impacts on air quality and energy use. The magnitude of potential impacts, however, depends on a number of factors such as the size of the city and its underlying climate. Hence, there is a need to develop a screening tool to provide urban planners with qualitative assessments of various mitigation options. The challenge is to develop a tool that can easily be applied to any major US city. Given the level of resources and computational effort required to model the effects of a specific mitigation strategy in detail for any one city, a streamlined modeling approach is useful as a screening step. As a result the US Environmental Protection Agency (EPA) commissioned a series of modeling studies (Taha and Sailor, 1997; Akbari and Konopacki, 2003; Sailor, 2003) that laid the foundation for the development of this tool.

\section{Overview of methods}

The Mitigation Impact Screening Tool (MIST) was developed to balance the need for a cost-effective and quick means of estimating performance of mitigation strategies in a wide range of cities and the requirement that the results from the tool be based on sound scientific methods. The general approach behind MIST involved first developing a full suite of detailed meteorological model simulations for a set of test cities (listed in Table 1). The suite of simulations consisted of control runs for existing historical episodes as well as mitigation scenario runs for several different levels of albedo and/or vegetation mitigation. The atmospheric effects of mitigation strategies were then extrapolated to other cities through regression analysis. This process involved identifying the key characteristics that determine the magnitude of impact on the urban climate (e.g., population, urban area extent, and latitude). The estimated local climatic effects of mitigation were then used as input to other models relating atmospheric conditions to the end points of interest - in this case, tropospheric ozone air quality and building energy consumption. 
Table 1

List of cities for which detailed meteorological modeling and subsequent statistical air quality modeling was performed

\begin{tabular}{|c|c|c|c|c|c|c|c|}
\hline City & State & Latitude & Longitude & Population (2000) & Annual CDD ( ${ }^{\circ} \mathrm{F}$ day) & Annual HDD ( ${ }^{\circ} \mathrm{F}$ day) & Area of $\mathrm{MSA}^{\mathrm{a}}\left(\mathrm{km}^{2}\right)$ \\
\hline Atlanta & GA & 33.65 & 84.42 & 4112198 & 1611 & 3090 & 16072 \\
\hline Bakersfield & $\mathrm{CA}$ & 35.43 & 119.05 & 661645 & 2367 & 2100 & 21129 \\
\hline Baltimore & MD & 39.18 & 76.67 & 2552994 & 1133 & 4912 & 8037 \\
\hline Baton Rouge & LA & 30.53 & 91.15 & 602894 & 2444 & 1653 & 4349 \\
\hline Charlotte & $\mathrm{NC}$ & 35.22 & 80.93 & 1499293 & 1513 & 3416 & 8908 \\
\hline Dallas & $\mathrm{TX}$ & 32.90 & 97.03 & 5221801 & 2603 & 2407 & 24515 \\
\hline Detroit & MI & 42.42 & 83.02 & 4441551 & 567 & 6726 & 11209 \\
\hline Fresno & $\mathrm{CA}$ & 36.77 & 119.72 & 922516 & 1884 & 2602 & 21153 \\
\hline Grand Rapids & MI & 42.88 & 85.52 & 1088514 & 508 & 7148 & 15007 \\
\hline Houston & $\mathrm{TX}$ & 29.97 & 95.35 & 4177646 & 2810 & 1552 & 16329 \\
\hline Los Angeles & $\mathrm{CA}$ & 33.93 & 118.40 & 16373645 & 470 & 1291 & 91431 \\
\hline Louisville & KY & 38.23 & 85.67 & 1025598 & 1300 & 4441 & 5435 \\
\hline New Orleans & LA & 29.98 & 90.25 & 1337726 & 2539 & 1464 & 19041 \\
\hline Philadelphia & PA & 39.88 & 75.25 & 5100931 & 1053 & 5181 & 10250 \\
\hline Phoenix & $\mathrm{AZ}$ & 33.43 & 112.02 & 3251876 & 3815 & 1154 & 37793 \\
\hline Sacramento & $\mathrm{CA}$ & 38.52 & 121.50 & 1628197 & 1144 & 2794 & 11097 \\
\hline San Diego & $\mathrm{CA}$ & 32.73 & 117.17 & 2813833 & 766 & 1076 & 11716 \\
\hline San Francisco & $\mathrm{CA}$ & 37.62 & 122.38 & 1731183 & 69 & 3239 & 4663 \\
\hline Tucson & $\mathrm{AZ}$ & 32.12 & 110.93 & 843746 & 2763 & 1554 & 23789 \\
\hline Washington & $\mathrm{DC}$ & 38.85 & 77.04 & 4923153 & 1549 & 5006 & 17914 \\
\hline
\end{tabular}

Results from these 20 cites form the basis of MIST.

${ }^{a}$ MSA, Metropolitan Statistical Area as defined by the US Census (www.census.gov).

The MIST automates the process of selecting a city and mitigation strategy for the investigation, extrapolates the impacts from the existing database of results from modeled cities, and summarizes the results for interpretation.

\section{Streamlined atmospheric modeling}

\subsection{The meteorological model}

Version 3.4 of the MM5 mesoscale model from the National Center for Atmospheric Research (Guo and Chen, 1994; Grell et al., 1995) is used in this analysis. The MM5 is a prognostic model useful for multi-day simulations of domains with horizontal extent ranging from tens to thousands of kilometers. It allows for nesting of higher resolution domains, and uses a uniform horizontal grid structure with a terrain-following vertical coordinate. As implemented in this work the MM5 model consists of four preprocessor steps, a model integration (forecast) step, and post-processing analyses. The MM5 model and its preprocessors each have control files that specify a large number of simulation options, ranging from parameterization of exchange processes at the surface to parameterization of cloud processes. While it is common practice to optimize the selection and combination of physics options for the particular geographic location and weather pattern under investigation, the underlying goal of this work dictated the standardization of model options across all cities and episodes modeled.

\subsection{Domain definitions}

In all simulations we defined three levels of nests with resolutions of $18 \mathrm{~km}, 6 \mathrm{~km}$, and $2 \mathrm{~km}$. The finest scale nests were centered over urban areas and in some cases a single simulation would include multiple $2 \mathrm{~km}$ nests covering multiple cities within general proximity to one another. Fig. 1 illustrates the typical nested domain structure. The land use data used to specify surface characteristics in all domains were from the MM5's default USGS land use database. The spatial resolution of these data is $30 \mathrm{~s}(\sim 0.9 \mathrm{~km})$. Recent aerial photos were used to make modest refinements to the default land cover data to account for changes in physical extent of the urban areas. Furthermore, the original "urban" land use category from the USGS categorization scheme was refined to allow for three urban subcategories - residential, commercial/industrial, and urban core. Surface characteristics for these land uses were modified from the default USGS values to better reflect surface characteristic variation within urban areas (see Sailor, 1998).

As noted above, in running the MM5 there are a large number of simulation parameters that need to be defined. These include the time step, definition of vertical model levels, parameters defining how observations are used in defining boundary/initial conditions, frequency of updating radiation calculations, choice of boundary-layer scheme, cloud physics, and other parameters. To ensure uniform application of the MM5 for all domains we adopted a fixed set of default options. The most significant of these parameters is summarized in Table 2 along with the associated default values for the control simulations.

\subsection{Control simulations}

Baseline and mitigation scenarios were based on the fundamental set of model parameters discussed above. For the baseline simulation all runs were initialized at midnight Greenwich 

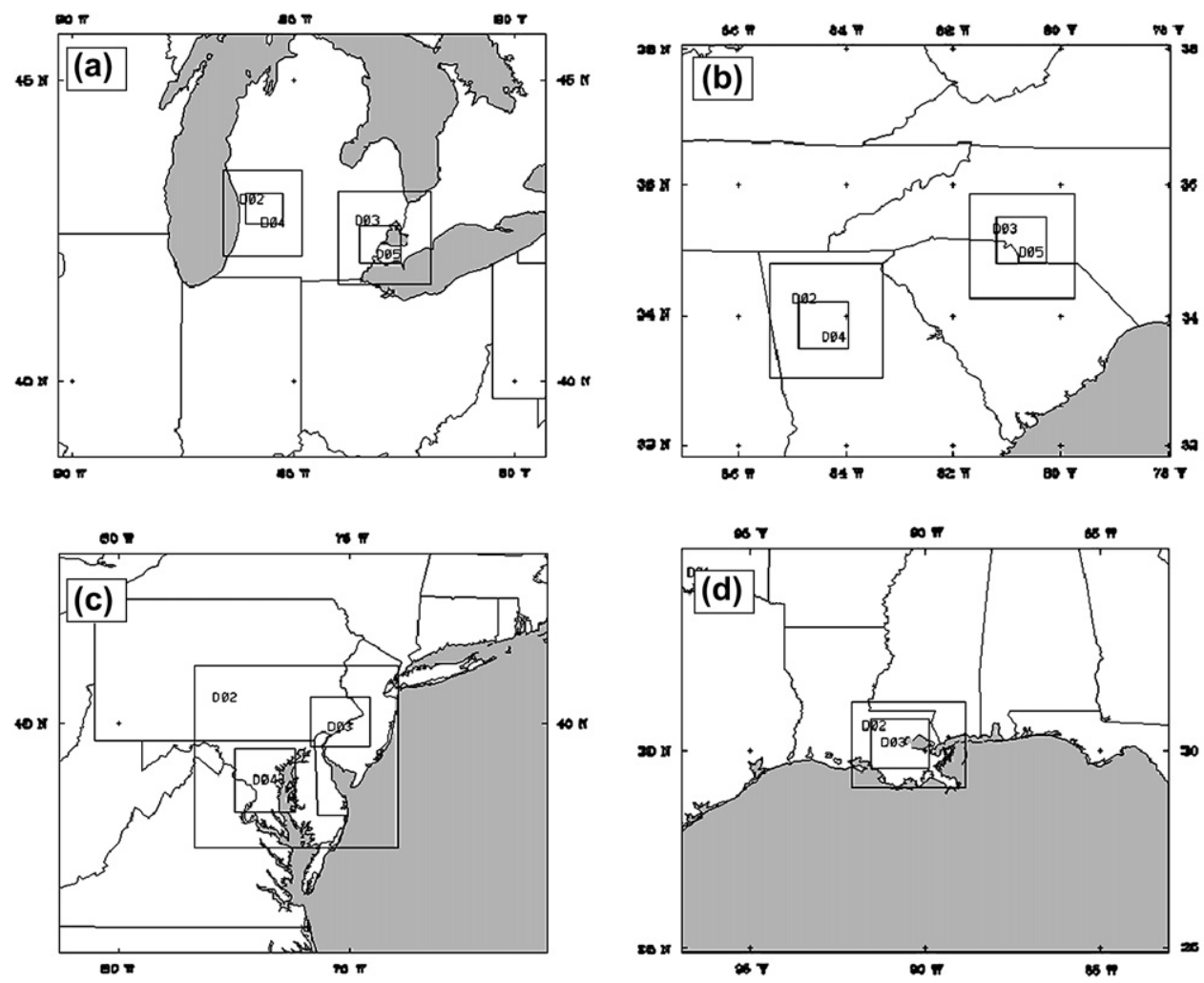

Fig. 1. Example MM5 modeling domains with fine-grid nests centered over various cites: (a) Detroit and Grand Rapids MI; (b) Atlanta GA and Charlotte NC; (c) Washington DC and Baltimore MD; and (d) New Orleans and Baton Rouge LA (both within same inner nest).

Mean Time (GMT) of the first day. The simulations were integrated forward in time for at least 30 simulation hours, and results were analyzed starting at the sixth hour of model simulation. This 6-h "spin-up" period is commonly used in atmospheric modeling to smooth out the model response to inherently inaccurate initial conditions. Initial simulations with longer spin-up periods did not significantly alter the analysis results. Most modeled episodes were 2-4 days in length. For these simulation domains (in the continental US), the initialization of midnight GMT corresponds to early evening of the previous day. A limited validation was performed where hourly temperature data from the nearest major airport weather station were compared with the near-surface air temperature predicted by the MM5 control simulations. Fig. 2 illustrates typical model performance for multi-day simulations. As can be seen in this figure, the MM5 is capable of capturing general diurnal characteristics as well as multi-day warming or cooling periods. Some of the deviations between

Table 2

Default MM5 model parameters used in all atmospheric model simulations

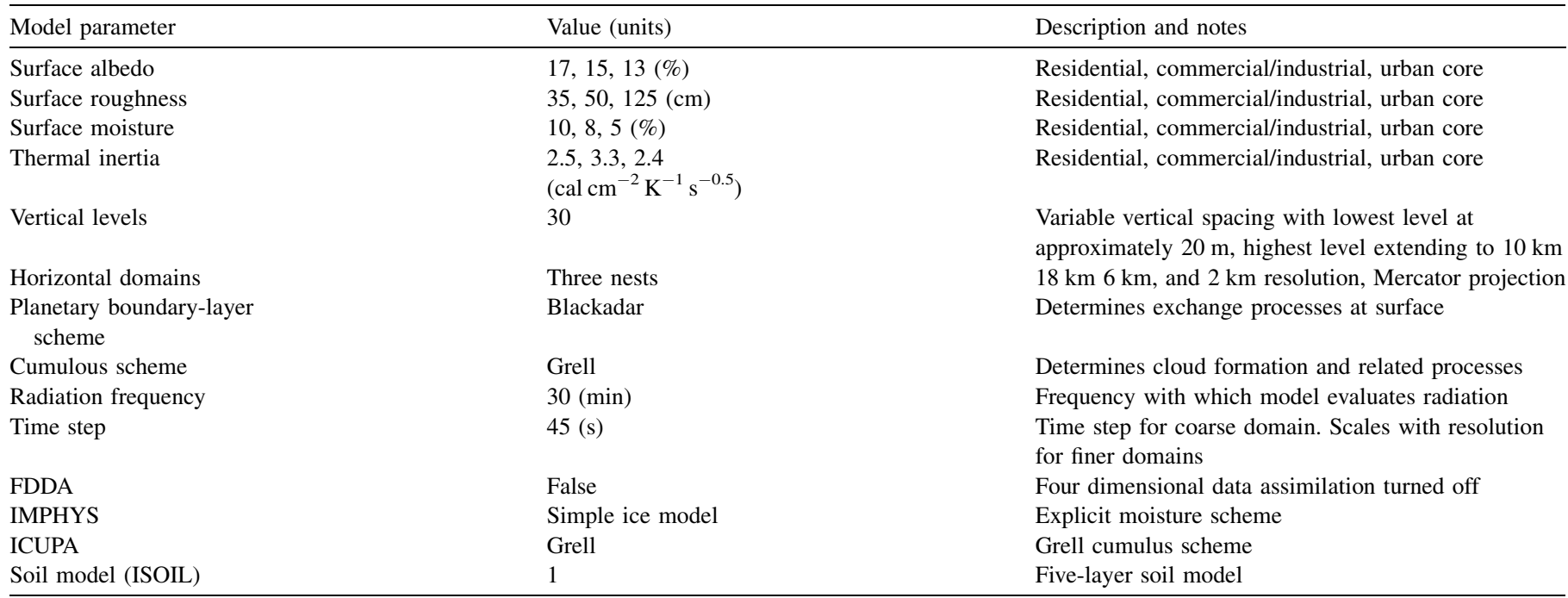

See Grell et al. (1995) for detailed descriptions of model parameter options. 
(a)

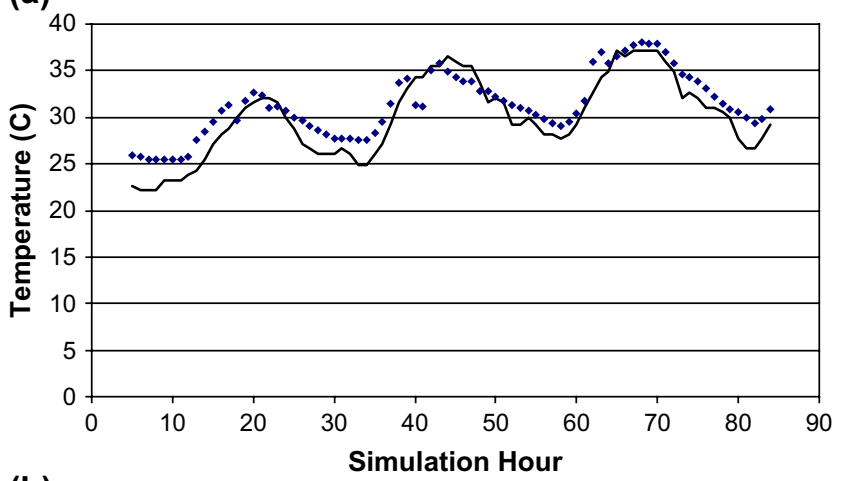

(b)

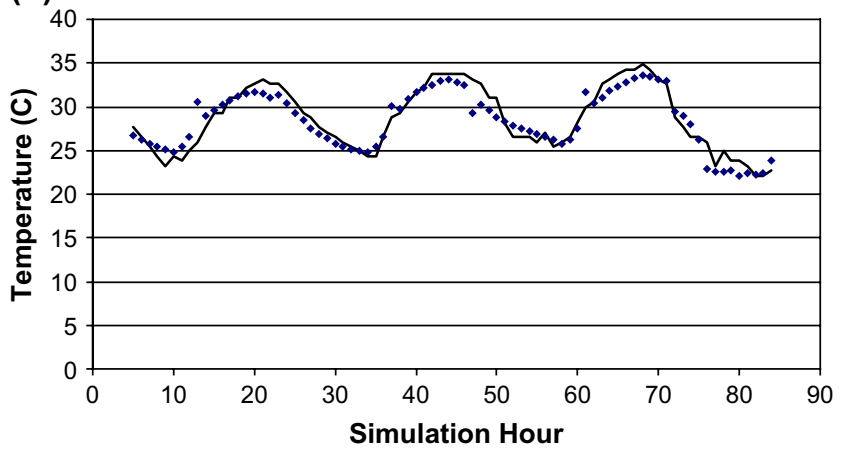

Fig. 2. Typical meteorological model performance for multi-day simulations for Philadelphia. Simulations are initiated at 00 GMT on (a) July 3, 1999, and (b) July 26, 1999. Solid line is observed air temperature at Philadelphia International Airport (PHL) and symbols are the MM5 model predictions averaged over the urban grid cells corresponding to the city of Philadelphia.

modeled and measured temperatures may be due to factors such as localized cloud cover, boundary-layer transitions affecting vertical mixing, and anomalies with weather station equipment. In an effort to capture key weather patterns contributing to poor air quality, multiple episodes (typically $2-4$ ) were modeled for each of the 20 test cities. Fig. 3 is a scatter plot of measured versus predicted air temperatures for all simulation hours for the Philadelphia domain. This figure represents 547 simulation hours over nine separate simulation episodes averaging $60 \mathrm{~h}$ each. The correlation exhibited in this figure is 0.89 and the root mean square error is $1.9^{\circ} \mathrm{C}$. These results are typical of all simulations conducted for all 20 test cities.

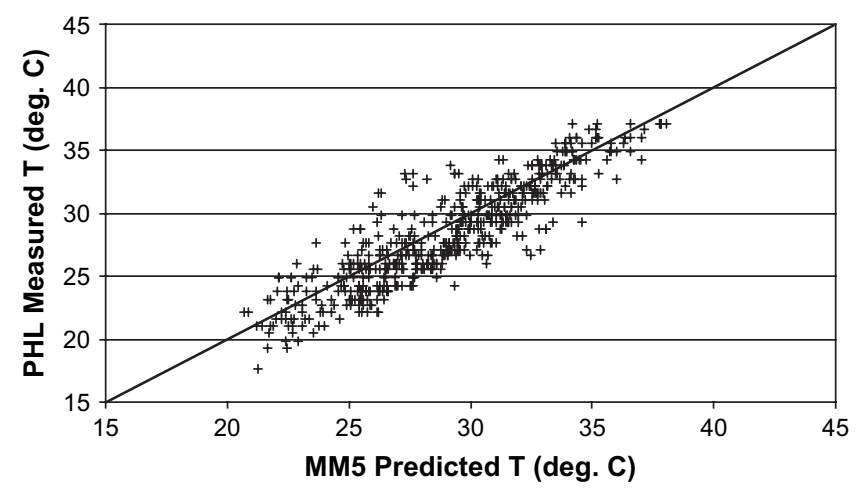

Fig. 3. Scatter plot illustrating correlation between meteorological model output and corresponding airport weather station. Philadelphia as an example. Solid line represents the line of perfect agreement.

\subsection{Mitigation simulations}

After running the baseline simulations we modeled surface changes to represent various mitigation scenarios. To implement these scenarios in the MM5 we altered the land use definition file to modify all urban cells. Mitigation scenarios were based on simple and uniform perturbations of surface characteristics for all urban (residential, commercial/industrial, and urban core) grid cells. Mitigation scenarios included cases of 0.1 and 0.2 increase in vegetative cover and albedo (separately and simultaneously). This level of modification is consistent with estimates of achievable potential for modification from several studies (Bretz et al., 1998; Akbari et al., 1999, 2001).

The albedo modification was implemented by directly modifying the albedo of each urban grid cell. This is possible because albedo is a fundamental parameter in the model. Vegetation, on the other hand, is not a fundamental parameter in the MM5 model. So it must be modeled through changes to other surrogate parameters. The approach we took was based on earlier work (Sailor, 1998) where we assume that adding vegetative cover to an urban grid cell is equivalent to replacing part of the urban land in that grid cell by a vegetative land cover class considered to be representative of urban vegetation. The surface characteristics of the urban land use were then modified to reflect an appropriate weighting between those corresponding to an urban cell and those corresponding to a completely vegetated cell. The USGS land use category used as a surrogate for urban vegetation is the Deciduous Broadleaf category. This land use differs from the urban land use categories primarily in terms of albedo, moisture availability, roughness, and thermal inertia, with values of $0.16,0.30,0.5 \mathrm{~m}$, and $4.0 \mathrm{cal} \mathrm{cm}^{-2} \mathrm{~K}^{-1} \mathrm{~s}^{-0.5}$, respectively.

For any surface characteristic, $P$, the effect of a fractional increase in vegetative cover $\left(f_{\text {veg }}\right)$ was modeled according to:

$P_{\text {new }}=P_{\text {non-veg }}\left(1-f_{\text {veg }}\right)+f_{\text {veg }} P_{\text {veg }}$

Accordingly, for $f_{\text {veg }}=0$ the grid cell is assigned purely urban characteristics $\left(P_{\text {non-veg }}\right)$, and as $f_{\text {veg }}$ approaches 1.0 the surface characteristics become those of completely vegetated land $\left(P_{\text {veg }}\right)$. As an example, consider an urban grid cell for which we wish to represent a 0.20 increase in vegetative cover. The initial urban moisture availability for this cell would be 0.10 . The moisture availability of a completely vegetated cell would be 0.30 . The moisture availability for the cell after an increase of 0.2 in vegetative cover would correspond to:

$M_{\text {new }}=0.10(1-0.20)+0.20 \times 0.30=0.14$

Upon completion of all meteorological model simulations the near-surface hourly air temperature averaged over each city was extracted from each control and mitigation run. The corresponding air temperature perturbation was then calculated for use in estimating air quality and energy impacts of the mitigation strategies. 


\subsection{Linking meteorology to ozone air quality impacts}

The traditional approach to modeling the impact of mitigation measures on ozone is to select one or several historical episodes for which national ambient air quality standards were violated and model these episodes first using the historical land use/cover and then using a set of modified surface characteristics (e.g., Taha and Sailor, 1997; Taha et al., 1998). The modeling includes both a mesoscale meteorological component and a photochemical component. The use of physically-based models in such a situation is generally desirable and under ideal circumstances should result in good predictive power. Furthermore, this approach has the support of the regulatory community. At the same time, there is concern that these models (with their numerous input parameters) can easily be overfit for a particular simulation domain and episode, or even for several episodes. In other words, it is possible to match key characteristics of an ozone episode through manipulation of model input parameters in ways that may be somewhat arbitrary. The result in such cases is a model that matches a particular episode quite well but has poor predictive power when applied to other episodes. This approach is also prohibitively resource intensive to implement for such a large number of test cities and episodes. For the purposes of this study a sophisticated but easily implemented statistical approach was desired. This streamlined air quality modeling approach is intended to identify the order-of-magnitude air quality impacts associated with a particular mitigation strategy.

The Tree Structured Regression (TSR) classification method represents a suitable compromise between accuracy and simplicity. TSR builds a binary-tree-like model with nodes (Breiman et al., 1984). Originally all the data points in the learning sample reside in a single root node. So if there are 500 historical days for use in model training the root node would contain the corresponding set of 500 data vectors. Each data vector consists of the dependent variable (e.g., ozone concentration), and a number of weather-related independent predictor variables. By posing and answering binary classification questions, every data point flows from the root node down to the next level of nodes. This classification process attempts to separate the data in any node into two distinct descendent nodes. The resubstitution estimate (RE) is then calculated as a sum of squared deviations from the mean within each of the descendent nodes:

$\mathrm{RE}=\sum_{i}\left[L_{i}-\bar{L}\right]^{2}+\sum_{i}\left[R_{i}-\bar{R}\right]^{2}$

where $L$ and $R$ represent values in the left and right descendent nodes, respectively, and the overbar indicates an average. The choice of binary question (which variable to use for the question and what value to use for the binary split) is determined through an automated optimization process that seeks to minimize RE for each node as the tree is developed.

When the tree is complete each data vector (day of data) resides in a terminal node that can be thought of as a unique weather pattern (e.g., hot, and humid). Within each terminal node a multiple linear regression (MLR) was used to predict peak ozone concentrations for the corresponding weather pattern. The EPA has two metrics of ozone air quality that it tracks for US cities. These are (1) the maximum ozone concentrations in any single hour (1-h ozone), and (2) the maximum average ozone concentrations over any consecutive 8 -h period (8-h ozone). Ozone air quality is considered to be unhealthy when the $1-\mathrm{h}$ and 8 -h values exceed $120 \mathrm{ppb}$ and $80 \mathrm{ppb}$, respectively. Hence, our analysis developed TSR ozone models for both the 1-h and 8-h standards.

The predictor variables we chose are largely based on the recommendations from existing EPA guidelines. Our models generally started with 10 predictors - day type, precipitation, pressure, previous day ozone, average relative humidity, average temperature, maximum temperature, average wind speed, temperature at the $850 \mathrm{hPa}$ (hectopascals) pressure level (T850), and geopotential height at the $500 \mathrm{hPa}$ level (HT500). All average variables were hourly observations averaged over the day time period from 8:00 a.m. to 7:00 p.m. (local time) to correspond to the time frame during which ozone precursors are emitted and converted to ozone via the complex photochemical reaction chain. Cloud cover data for many of the cities are incomplete and so were not included in our final analysis. Our "day type" variable replaced the day of week variable suggested in EPA guidelines for ozone modeling. The day type variable has two possible values, workday or non-workday. The main point of this parameter is to separate out days that may have more substantial emissions (weekdays). As it turns out the TSR methodology consistently resulted in models for which temperature and humidity variables dominated the tree structure. Temperature is important as it is highly correlated to emissions rates from biogenic and anthropogenic sources. Temperature is also an important parameter due to its role in determining rate constants for many important atmospheric chemistry reactions that are part of the complex ozone formation/destruction cycle. Humidity can be important in affecting ozone in part due to its role in pollutant removal by vegetation and also the way in which water vapor affects several important reactions in the photochemical cycle.

Commercial software (Cubist - www.rulequest.com) and up to 5 years of historical data (1995-1999) were used to generate ozone models for each of the study cities. The required ozone concentration data were obtained from the EPA AIRS database (www.epa.gov/air/data). The weather data were obtained from the National Climatic Data Center's Surface Airways database (www.ncdc.noaa.gov). A sample tree is illustrated in Fig. 4. In this figure there are 1127 training points (days of data) in the root node.

The first binary question that resulted from the optimization process for the example in Fig. 4 is "Is RH_avg $<68.7 \%$ ?" As indicated in the figure 848 days satisfied this criterion. Of these only 123 days also had average temperatures above $26.7^{\circ} \mathrm{C}$ and $\mathrm{RH}$ (relative humidity) less than $51.6 \%$. In this TSR model for Atlanta the two weather patterns that are most important for ozone are the bottom two nodes in this figure. The corresponding average $1 \mathrm{~h}$ peak ozone values in these weather patterns (shown 


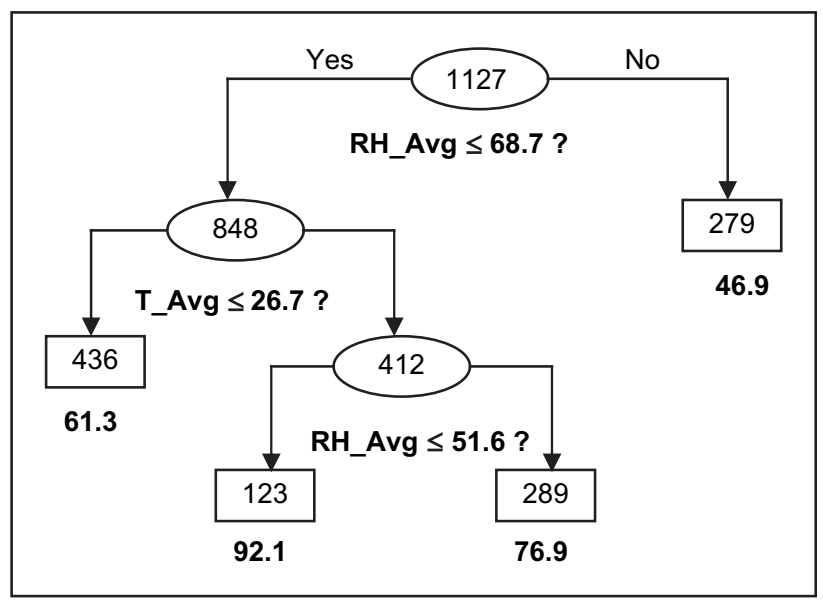

Fig. 4. Sample tree for $1 \mathrm{~h}$ ozone in Atlanta (average over 12 stations). Ovals and boxes represent intermediate and terminal nodes, respectively. Numbers within ovals/boxes indicate number of data points satisfying a particular set of conditions. Numbers below terminal nodes indicate the corresponding mean ozone concentrations.

in bold under the corresponding node) are $92.1 \mathrm{ppb}$ and $76.9 \mathrm{ppb}$, respectively. Within each of these terminal nodes an additional multiple linear regression was performed to generate a model of how ozone responds to changes in weather parameters. The final ozone model correlation coefficients ranged from 0.61 to 0.86 with an average of 0.75 and 0.74 for the $1-\mathrm{h}$ and $8-\mathrm{h}$ models, respectively. The corresponding average absolute model error ranged from $7.9 \mathrm{ppb}$ to $13.4 \mathrm{ppb}$ ozone. Hence, it can be concluded that the TSR-based ozone models perform well when compared with observations.

With TSR models of ozone concentrations established for any city it is relatively straightforward to replace the historical data with perturbed weather corresponding to any mitigation strategy. The result is an estimate of the changes in ozone concentrations that could be expected for various levels of urban heat island mitigation. As temperature perturbations are the dominant factor affecting the response of ozone concentrations to mitigation strategies we defined two sensitivity parameters relating changes in ozone concentration to changes in mean air temperature. One factor $\left(B_{-} \_\right.$h) was calculated for the 1-hour ozone models and a second factor (B_8 $\mathrm{h}$ ) for the 8-h ozone models. Each factor has units of ppb per degree C. Since ozone concentrations generally increase with temperature these factors are positive and are generally in the range of $1-4 \mathrm{ppb}$ per degree celsius.

\subsection{Linking meteorology to energy consumption impacts}

While ozone impact modeling is temperature-based, energy models are typically developed in terms of the relationship between consumption and the derived parameters of Cooling Degree Days (CDD) and Heating Degree Days (HDDs). These parameters reflect the demand for air conditioning and heating, respectively. In a plot of temperature versus time, CDD is the area that is both below the observed air temperature and above a threshold constant (usually $65^{\circ} \mathrm{F}$ ). HDD is the corresponding area below the threshold constant. In equation form these definitions are as follows:

$\mathrm{CDD}=\sum_{d=1}^{N_{\mathrm{d}}}\left(\gamma_{\mathrm{d}}\right)\left(T-T_{\mathrm{b}}\right)$

and

$\mathrm{HDD}=\sum_{d=1}^{N_{\mathrm{d}}}\left(1-\gamma_{\mathrm{d}}\right)\left(T_{\mathrm{b}}-T\right)$

In Eqs. (4) and (5) $N_{\mathrm{d}}$ is the number of days in a particular month, and $T$ is the mean daily temperature. The binary multiplier $\gamma_{\mathrm{d}}$ takes on a value of 1 if the daily temperature is higher than the base, and zero otherwise. The base temperature, $T_{\mathrm{b}}$, for degree day calculations is $18.3^{\circ} \mathrm{C}$.

Using actual hourly meteorological data from the 20 focus cities we calculated the nominal impact of a $1{ }^{\circ} \mathrm{C}$ temperature reduction (assumed uniform throughout the day) on both CDD and HDD. The results were regressed against CDD and HDD to determine functional relationships of the form:

$$
\begin{aligned}
\Delta \mathrm{CDD}= & -0.47+1.1 \mathrm{E}-04 \times \mathrm{CDD}+3.4 \mathrm{E}-05 \\
& \times \operatorname{HDD}(R=0.91) \\
\Delta \mathrm{HDD}= & 0.30-3.7 \mathrm{E}-05 \times \mathrm{CDD}-3.3 \mathrm{E}-05 \\
& \times \mathrm{HDD}(R=0.92)
\end{aligned}
$$
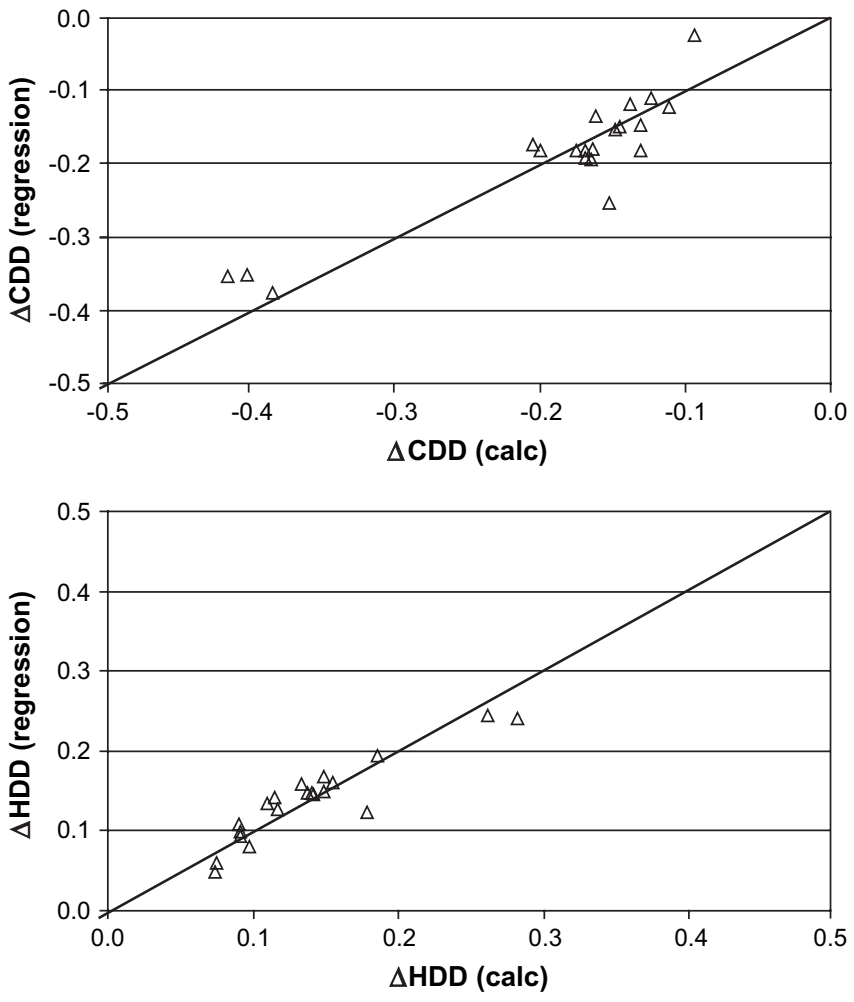

Fig. 5. Scatter plots for sensitivity of annual CDD and HDD to a $1{ }^{\circ} \mathrm{C}$ reduction in air temperature. Regression results plotted against sensitivity calculated directly from hourly temperature data. 
The values of $\triangle \mathrm{CDD}$ and $\triangle \mathrm{HDD}$ then represent the fractional change in degree days associated with a $1.0{ }^{\circ} \mathrm{C}$ reduction in air temperature. For example, a value of $\Delta \mathrm{CDD}=-0.15$ implies that a $1.0^{\circ} \mathrm{C}$ reduction in air temperature will reduce Cooling Degree Days by $15 \%$. For the purposes of MIST it was assumed that for temperature perturbations near $1.0^{\circ} \mathrm{C}$ the impact on degree days is approximately linear. That is, $\triangle \mathrm{CDD}$ and $\triangle \mathrm{HDD}$ obtained from the above regressions can simply be multiplied by $\Delta T$. Scatter plots for these regressions are given in Fig. 5.

The energy models themselves were obtained from an analysis conducted by Lawrence Berkeley National Laboratory (Akbari and Konopacki, 2003). For each city of their analysis specific building archetypes were modeled using the DoE-2 building energy analysis software. As building codes and insulation levels have evolved over time, LBNL presents results for both "pre-1980" and "post-1980" buildings. By modifying both the building envelope definition and the "typical meteorological year" weather data LBNL was able to simulate both the direct and the indirect effects of increasing building albedo and vegetative cover. By combining results from meteorological simulations and building energy simulations they developed estimates of how a particular mitigation strategy would impact energy consumption and peak power for residential, office, and retail space on a per $1000 \mathrm{ft}^{2}\left(93 \mathrm{~m}^{2}\right)$ roof area basis. The LBNL meteorological simulations were developed using the same MM5 model and similar modeling techniques to those presented here.
The LBNL modeling focused on buildings in a small set of cities. To apply these results across a wider range of cities they conducted two classification analyses to relate energy impacts to either CDD or HDD. They defined $11 \mathrm{CDD}$ groups and 15 HDD groups to represent the impacts across different climates. Thus, the energy impacts can be estimated using either the CDD similarity or the HDD similarity approach. In all cases the energy modeling of mitigation strategies took into account both the energy savings in summer and the increased energy usage in winter.

\section{Software implementation}

\subsection{MIST structure}

The Mitigation Impact Screening Tool (MIST) is intended to provide qualitatively accurate assessments of the likely impacts of heat island mitigation strategies averaged at the cityscale. All results presented in this tool were obtained using the state-of-the-science modeling approaches discussed above. Nevertheless, the required assumptions and approximations dictate that the results presented by MIST are qualitative in nature. Users of the software are therefore instructed to use MIST for preliminary evaluation of mitigation strategies and are encouraged to pursue more detailed analyses prior to full scale implementation of a particular mitigation strategy.

The mitigation strategies investigated include increasing urban albedo and/or increasing urban vegetative cover. MIST

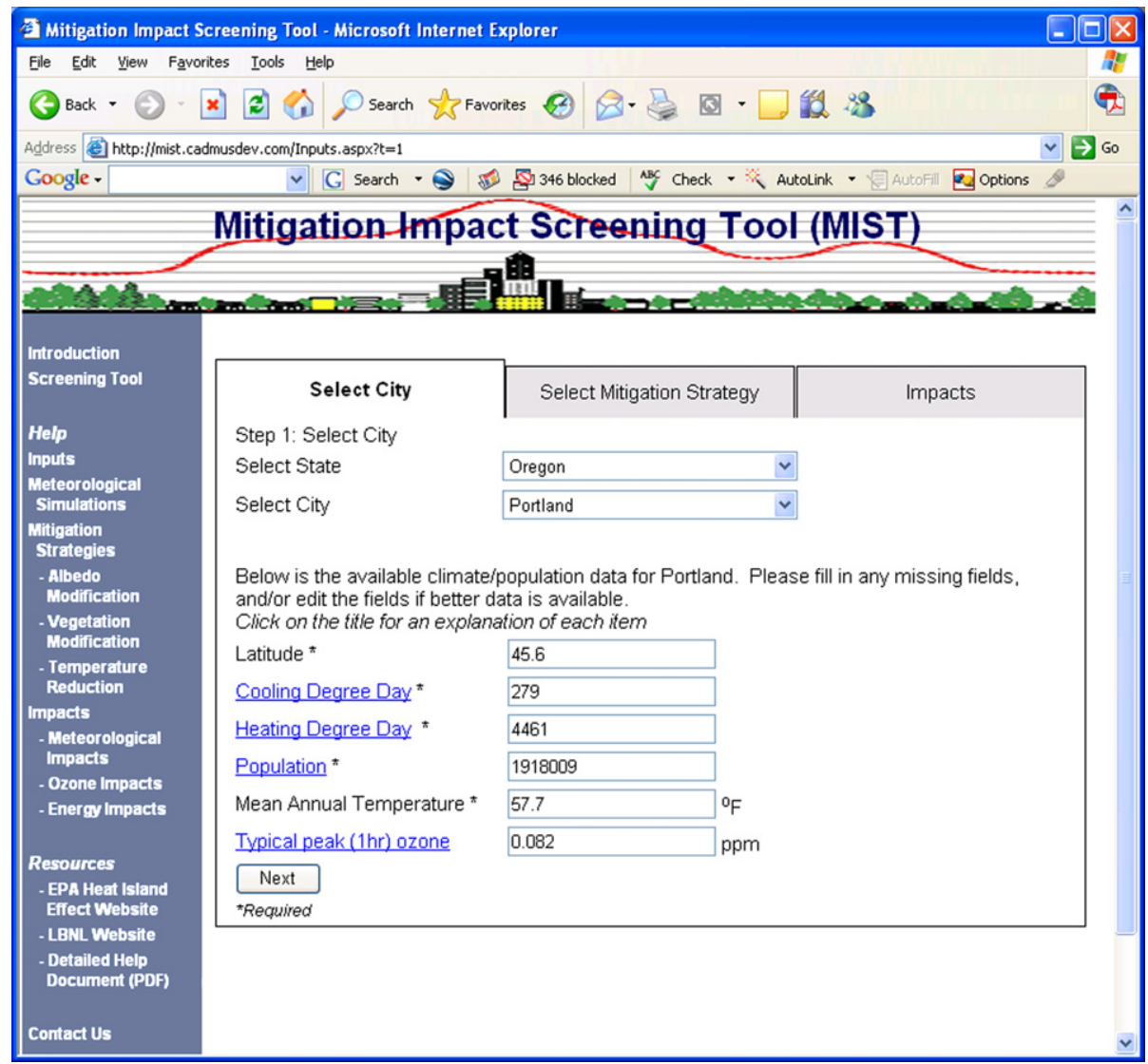

Fig. 6. Screenshot of the city selection portion of MIST. 
also allows investigation of a user-defined average temperature reduction and produces estimates of the resulting impacts on ozone and energy consumption.

There are three basic steps involved in running MIST: (1) select the city to model; (2) define the mitigation strategy to test; and (3) estimate impacts on meteorology, air quality, and energy. The software interface is organized around these steps with corresponding user-selectable tabs.

\subsection{City selection}

Data necessary to run the MIST code are available for approximately 240 major cities throughout the US. Fig. 6 shows a screenshot of the city selection portion of MIST in the current version of the tool. The user simply scrolls down the list of states and corresponding cities and clicks on the city of interest. The advanced user has the option of editing any or all of the city-specific model input parameters. When the city selection and any parameter edits are complete the user clicks on the "Next" button to move onto the mitigation strategy component of MIST.

\subsection{Mitigation strategy}

The user may select a vegetation, albedo, or combined mitigation strategy to model (Fig. 7). In all cases the mitigation level represents a fractional increase over the entire city, and the distribution of the change is assumed to be uniform over all urban areas. For example, suppose the city surface is $40 \%$ rooftop, $25 \%$ paved surface, and $35 \%$ vegetated surface. If the user specifies an increase of 0.1 in vegetative fraction, this corresponds to the assumption that the total vegetative cover of the city increases uniformly from $35 \%$ to $45 \%$. Likewise a specified increase of 0.10 in city albedo is assumed to be applied uniformly over the entire city. In practice, of course, this could be accomplished in many ways. For example, consider the case where the urban albedo is increased by 0.10 by modifying only rooftops. Since rooftops account for only $40 \%$ of the surface area in this example one would need to increase rooftop albedo by 0.25 to affect a city-wide average increase of albedo of 0.10 (i.e., $0.25 \times 0.40=0.10$ ). The MIST code is not capable of discerning spatial differences in application of either mitigation strategy, however, so all mitigation is assumed uniform over the city. As a result, users of MIST cannot explore questions related to where within the city mitigation strategies might be most effectively applied. For example, how might focusing mitigation within the central business district compare with a similar strategy focused on the suburbs?

The MIST code limits the range to $-0.5<\Delta<0.5$ for changes in either albedo or vegetation. This is primarily to limit the chance of entry errors (e.g., 10 rather than 0.10 ). In either case the level of mitigation specified by the user is converted directly to projected changes in near-surface air temperatures using results from mesoscale atmospheric modeling studies, as discussed in Section 5.4.1. Alternatively the user may simply input a uniform temperature perturbation. This

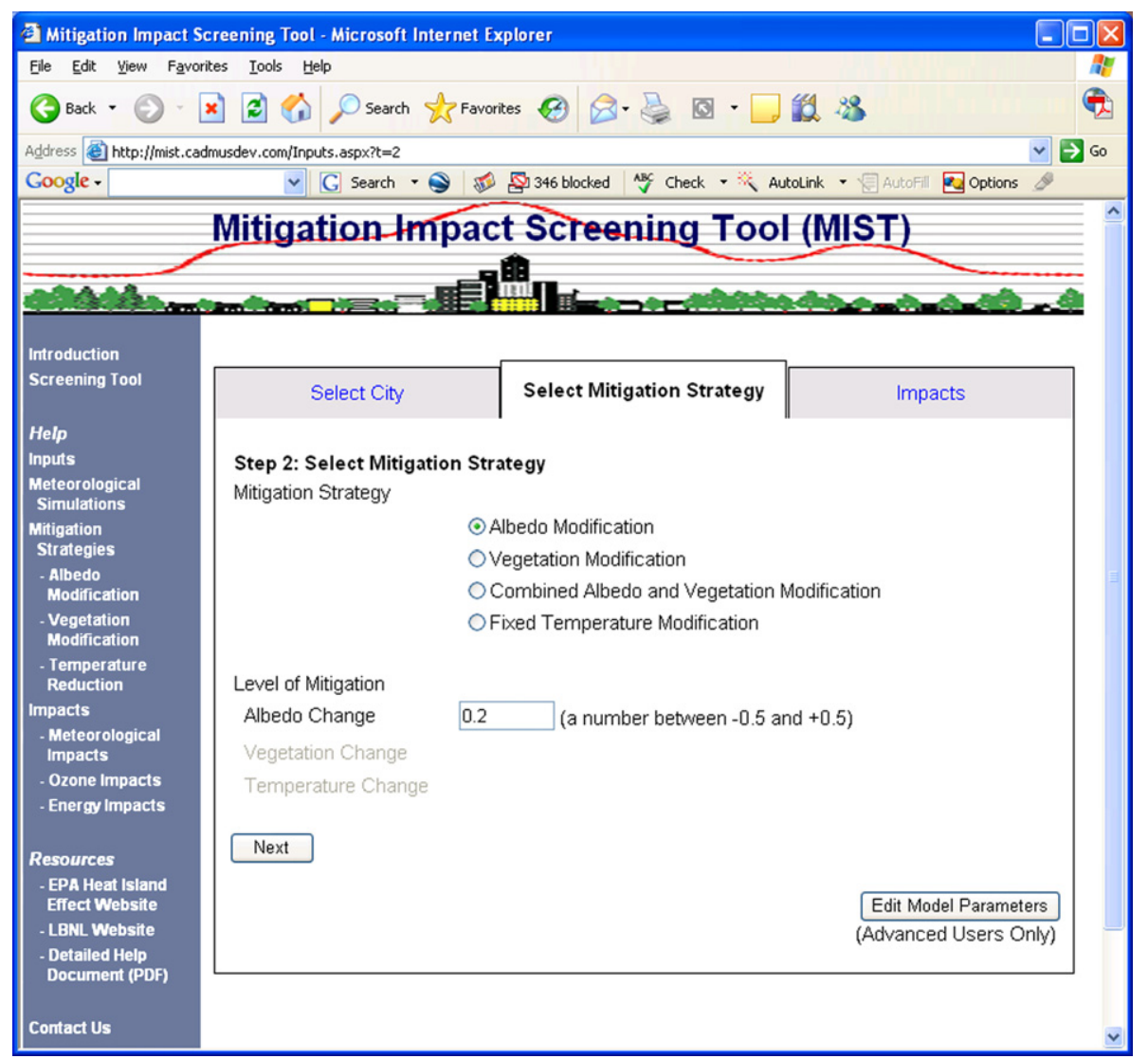

Fig. 7. Mitigation strategy options in MIST. 
option directly implements a change in near-surface air temperature, which is assumed uniform in space and time.

In this component of MIST the advanced user is again able to modify model parameters. After selecting a mitigation strategy the user clicks on the "Next" button to move onto the impacts component of MIST.

\subsection{Impacts estimation}

Urban heat island mitigation strategies can impact the urban environment in two distinct ways: directly and indirectly. The direct impacts of mitigation strategies are those that result from direct modification of the surface energy balance of buildings. For example, when a rooftop reflectivity (albedo) is increased the roof remains cooler under the hot summer sun and as a result the building's cooling load (and air conditioning energy consumption) is reduced. In addition, the implementation of heat island mitigation strategies can have an indirect impact on the entire city. For example, when rooftops are cooled through the implementation of a high-albedo strategy they convect less heat to the air that flows over them. The result is a city-scale cooling of near-surface air temperatures. If the mitigation strategy has sufficient spatial extent this indirect cooling can impact city-scale temperatures, air quality, and energy consumption. This effect has been demonstrated in regional scale simulations of various mitigation strategies (Sailor, 2003; Taha, 2003). In MIST the indirect impacts on ozone and the total (direct plus indirect) impacts on energy consumption are estimated using the methods presented above. These estimates are summarized at the top of the impacts estimation section of MIST (shown in Fig. 8). More detailed output can be viewed by scrolling down on the impacts page (Fig. 9). A "Print Results" tab enables the user to access a printer-friendly version of the results.

\subsubsection{Meteorological impacts}

Results from meteorological simulations in which the albedo and/or vegetation of cities was modified were used to explicitly provide estimates of the temperature impacts of surface characteristic perturbations (S_alb, and S_veg) for the study cities. Each sensitivity parameter represents the change in temperature in degrees celsius for a 0.1 increase in albedo or vegetative cover. Results for other cities are extrapolated from this set. Six city-specific variables - population, physical area, population density (resident population/ area), latitude, and underlying climate as measured by Cooling and Heating Degree Days - were considered for this extrapolation process. The population of the Metropolitan Statistical Area (MSA) was found to be the single most statistically significant determinant of S_alb, and S_veg for the modeled

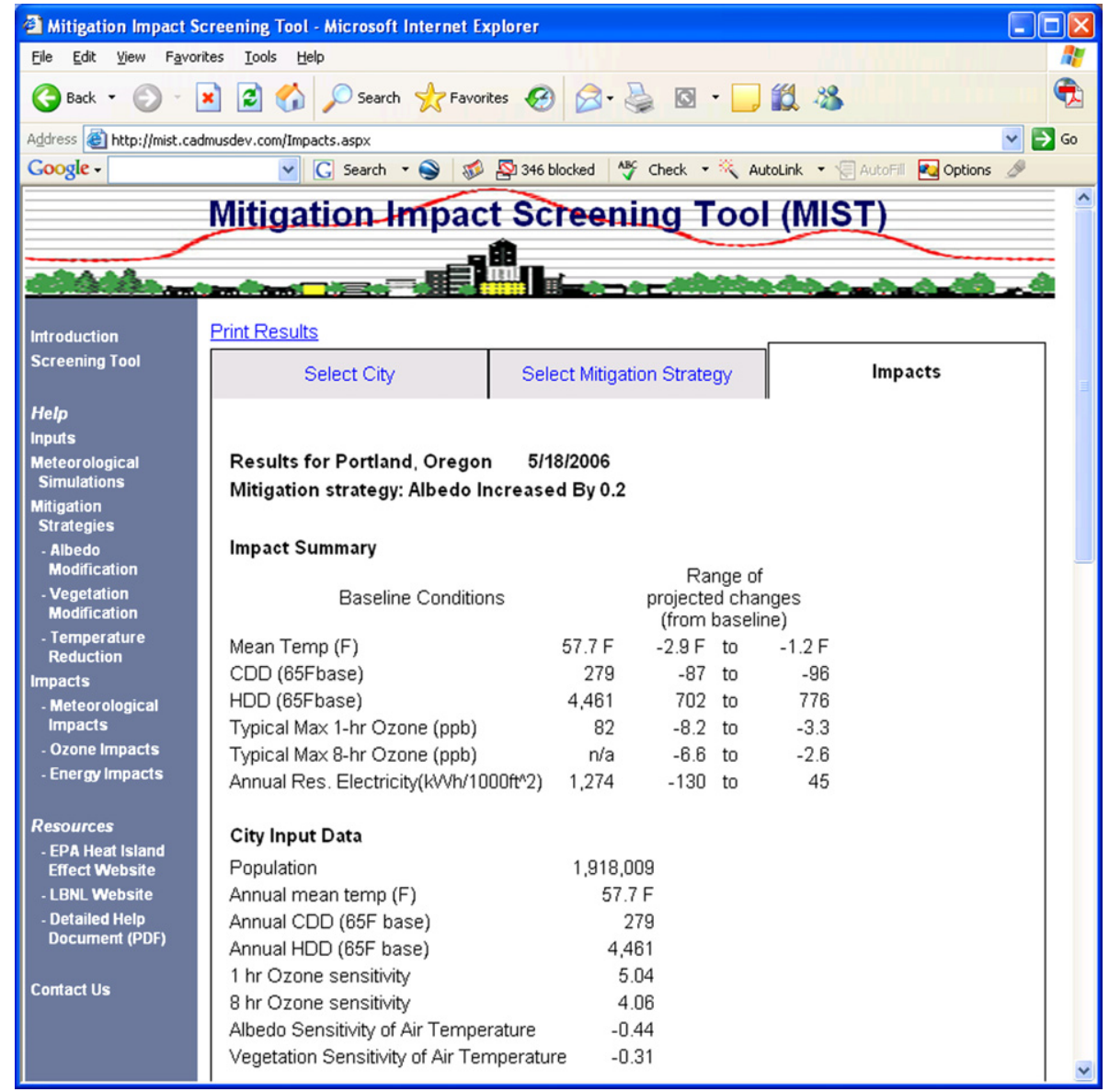

Fig. 8. Impact summary section of MIST. 
cities. Fig. 10 shows the resulting regressions which are of the form:

S_alb $=-2.8 \mathrm{E}-8 \times$ Population $-0.389(R=0.67)$

S_veg $=-1.6 \mathrm{E}-8 \times$ Population $-0.279(R=0.69)$

The uncertainty in the S_alb, and S_veg coefficients is estimated (using $+/-2 \sigma$ ) to be 0.24 , and 0.13 , respectively.

As weather patterns corresponding to representative bad air quality days were the focus of all meteorological modeling, the impacts on meteorology are inherently biased toward summertime impacts. The impacts for the small suite of simulations conducted for any individual city are then assumed to be uniform spatially and throughout the year. For the ozone impacts analysis this assumption is reasonable as peak ozone occurs during summer months. For the energy impacts analysis, however, the focus on summertime simulations introduces error into estimates of the wintertime heating costs. The implications of this error are discussed in Section 5.4.3.

\subsubsection{Ozone impacts}

The ozone sensitivity factors introduced above, B_ $1 \mathrm{~h}$ and B_ $8 \mathrm{~h}$ are different for different cities. While it is reasonable to suspect that their values will be influenced by city size and underlying climate a multiple linear regression analysis for the 20 test cities revealed the best two parameter models are those involving latitude and metropolitan area population:

$$
\begin{aligned}
\text { B_1h }= & -6.02+0.237 \times \text { Latitude }+1.30 \mathrm{E}-7 \\
& \times \text { Population }(R=0.76) \\
\text { B_8h }= & -5.21+0.199 \times \text { Latitude }+1.04 \mathrm{E}-7 \\
& \times \text { Population }(R=0.74)
\end{aligned}
$$

Scatter plots comparing this regression to the actual TSR model results for the 20 cities are shown in Fig. 11. The estimated uncertainties in B_1 h and B_8 h (based on $2 \sigma$ ) are $0.4 \mathrm{ppb}$ and $0.3 \mathrm{ppb}$ per degree celsius, respectively.

MIST estimates ozone impacts of mitigation strategies by combining the estimated air temperature impacts with the

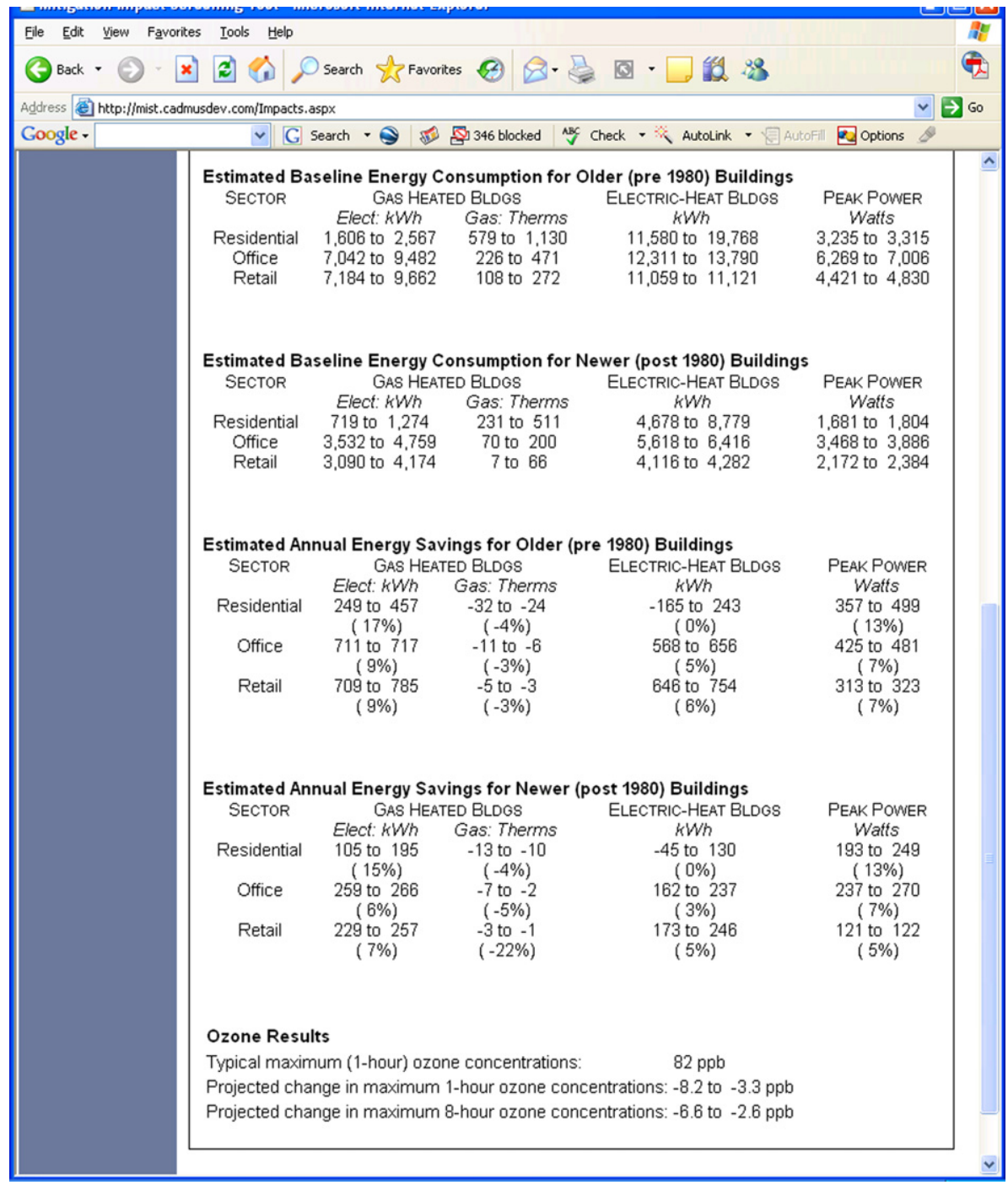

Fig. 9. Sample screenshot of MIST output for a 0.2 increase in albedo for the city of Portland Oregon. 
(a)

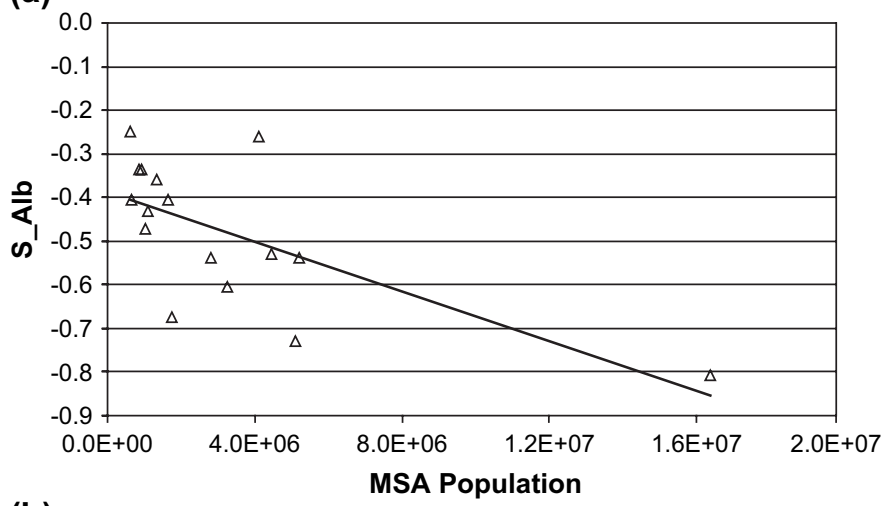

(b)

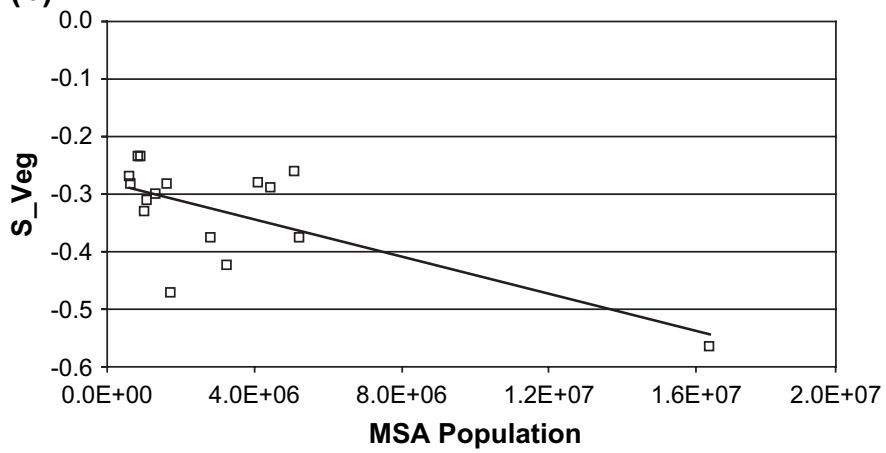

Fig. 10. Scatter plots of mitigation strategy sensitivity parameters (a) S_alb, and (b) S_veg plotted against metropolitan population. Solid lines represent regressions through the data (Eqs. (5) and (6)). Units of S_alb and S_veg are degree celsius per 0.1 change in albedo and vegetation, respectively.

(a)

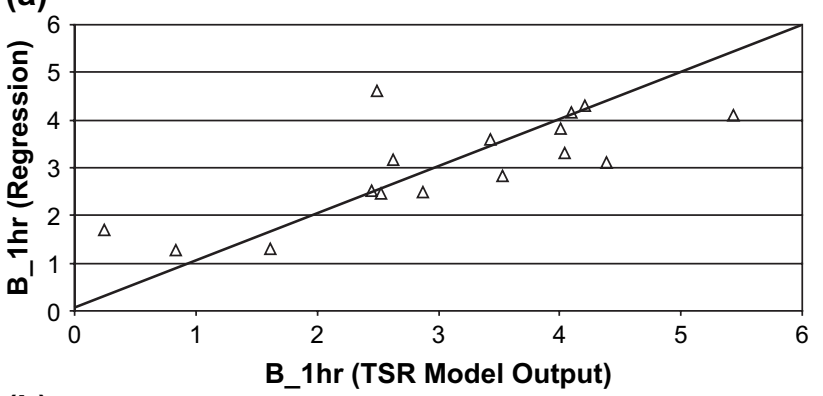

(b)

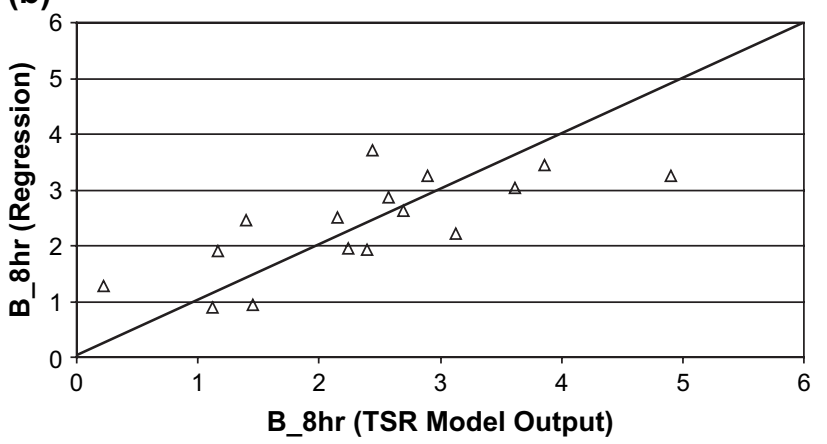

Fig. 11. Scatter plots comparing TSR-predicted ozone sensitivity factors to results from multiple linear regression curve fits (see Eqs. (7) and (8)). Units are ppb per degree celsius. ozone sensitivity factors. As an example, Akron, Ohio (latitude 40.92 degrees, metropolitan area population 694960 ) is not among the cities directly modeled for this study. So, the temperature impact of a 0.2 increase in albedo for Akron would be estimated as $-0.82{ }^{\circ} \mathrm{C}$ using Eq. (8). The corresponding 1-h ozone sensitivity would be $3.8 \mathrm{ppb}$ per degree celsius (using Eq. (10)). Hence MIST would project that a 0.2 increase in the albedo of Akron would reduce 1-h ozone peaks by an average of $3.2 \mathrm{ppb}$.

\subsubsection{Energy impacts}

As noted above a detailed description of the energy models implemented in MIST can be found in Akbari and Konopacki (2003). The energy portion of the MIST impacts tab summarizes current and estimated changes in energy consumption (and peak consumption) for prototypical residential (res), office (off), and retail (ret) buildings for both pre-1980 and post-1980 construction. Natural gas (Therms) and Electricity $(\mathrm{kW})$ data are presented in terms of consumption per $1000 \mathrm{ft}^{2}\left(93 \mathrm{~m}^{2}\right)$ of roof area. The energy results presented in the summary portion of the impacts section of MIST summarize just the residential (post-1980 construction) results before and after the implementation of a mitigation strategy as a general indicator of the magnitude of energy impacts.

As noted above, all meteorological simulations were conducted with a focus on summertime impacts of mitigation strategies. As a result, the analysis of wintertime impacts of mitigation strategies on energy (heating demand) is likely to be less accurate. Specifically, the mitigation strategies are directly linked to the magnitude of solar radiation. Increasing the albedo of surfaces results in a higher percentage of solar radiation being reflected out of the city. Since solar radiation is a more important component of the urban energy balance in summer we expect that albedo-based mitigation strategies will have more of a cooling effect in summer. Increasing the vegetative cover in a city results in higher levels of evaporative cooling. This effect is less significant in winter months when lower solar radiation and lower air temperatures result in reduced potential for evapotranspiration from plants. Hence, in summer months the cooling effect of mitigation strategies should be largest. While cooling in summer is beneficial, cooling in winter would result in increased energy use for heating. By assuming winter cooling comparable to summer we are, in effect, overestimating the wintertime heating penalty associated with mitigation strategies. Hence, this assumption leads to a conservative estimate of the annualized energy savings.

\section{Conclusions}

In response to the need of urban planners for an easy-to-use screening tool to estimate the potential impacts of urban heat island mitigation strategies on their cities we have developed the Mitigation Impact Screening Tool (MIST). The initial development of MIST was in Visual Basic. The web-based version of the tool can be accessed from the US EPA's Heat Island website (www.epa.gov/heatisland). This software tool 
is based on streamlined mesoscale atmospheric modeling for the test cities combined with statistical models relating weather parameters to ozone and physically-based computer models of building energy consumption. MIST allows for extrapolation of these results to a wide range of cities. The end result is a screening tool that can be used to estimate the possible benefits of a range of heat island mitigation strategies for over 170 US cities. Given the significant number of assumptions, approximations, and extrapolations used in the software development and implementation process, MIST should not be used as the basis for regulatory decision-making. Rather, MIST should be used to provide an initial feasibility assessment. If results from this assessment are promising planners may wish to pursue a more detailed analysis using traditional methods (e.g., detailed meteorological and photochemical modeling).

\section{Acknowledgments}

The authors wish to acknowledge the helpful pre-submission review comments of Eva Wong (US EPA), Jamie Voogt (University of Western Ontario), Gordon Heisler (USDA Forest Service), and David Hitchcock (Houston Advanced Research Center). This material is based upon work supported by the US Environmental Protection Agency under Subcontract 02029-06 of EPA Contract 68W02029. Any opinions, findings, and conclusions or recommendations expressed in this material are those of the authors and do not necessarily reflect the views of the Environmental Protection Agency.

\section{References}

Akbari, H., 2002. Shade trees reduce building energy use and $\mathrm{CO}_{2}$ emissions from power plants. Environmental Pollution 116 (1), S119-S126.

Akbari, H., Konopacki, S., 2003. Streamlined Energy-savings Calculations for Heat-island Reduction Strategies - Final Report. LBNL-47307. LBNL, $110 \mathrm{pp}$.

Akbari, H., Pomerantz, M., Taha, H., 2001. Cool surfaces and shade trees to reduce energy use and improve air quality in urban areas. Solar Energy 70 (3), 295-310.

Akbari, H., Rose, L.R., Taha, H., 1999. Characterizing the Fabric of the Urban Environment: A Case Study of Sacramento. Lawrence Berkeley National Laboratory, Report, Berkeley. LBNL-44688.

Bornstein, R., Lin, Q., 2000. Urban heat islands and summertime convective thunderstorms in Atlanta: three case studies. Atmospheric Environment 34 (3), 507-516.

Bretz, S., Akbari, H., Rosenfeld, A., 1998. Practical issues for using solar-reflective materials to mitigate urban heat islands. Atmospheric Environment 32 (1), 95-101.

Breiman, L., Freidman, J.H., Stone, C.J., Olshen, R.A., 1984. Classification and Regression Trees, 391 pp. CRC Press, Boca Raton. ISBN: 0-412-04841-8.

Estes Jr., M.G., 2000. Urban heat island mitigation strategies. Planning Advisory Service Memo (May) 1-4.

Feingersh, T., Ben-Dor, E., Portugali, J., 2007. Construction of synthetic spectral reflectance of remotely sensed imagery for planning purposes. Environmental Modelling \& Software 22 (3), 335-348.

Grell, G., Dudhia, J., Stauffer, D., 1995. A Description of the Fifth-generation Penn State/NCAR Mesoscale Model (MM5). NCAR/TN-398, 122 pp.
Guo, Y.-R., Chen, S., 1994. Terrain and Land Use for the Fifth-Generation Penn State/NCAR Mesoscale Modeling System (MM5): Program TERRAIN. pp. NCAR/TN-397 + IA.

Herbert, J.M., Johnson, G.T., Arnfield, A.J., 1998. Modelling the thermal climate in city canyons. Environmental Modelling and Software 13 (3-4), 267-277.

Kusaka, H., Kimura, F., 2004. Coupling a single-layer urban canopy model with a simple atmospheric model: impact on urban heat island simulation for an idealized case. Journal of the Meteorological Society of Japan 82 (1), 67-80.

Landsberg, H.E., 1981. The Urban Climate. Academic Press.

Lemonsu, A., Masson, V., 2002. Simulation of a summer urban breeze over Paris. Boundary-Layer Meteorology 104 (3), 463-490.

Morris, C.J.G., Simmonds, I., 2001. Quantification of the influence of wind and cloud on the nocturnal urban heat island of a large city. Journal of Applied Meteorology 40 (2), 169-182.

Nielsen-Gammon, J.W., 2000. The Houston heat pump: modulation of a landsea breeze by an urban heat island. In: Eleventh Conference on Air Pollution Meteorology, Long Beach, AMS.

Oke, T.R., 1981. Canyon geometry and the nocturnal urban heat island: comparison of scale model and field observations. Journal of Climatology 1 (3), 237-254.

Oke, T.R., 1982. The energetic basis of the urban heat island. Quarterly Journal of the Royal Meteorological Society 108, 1-24.

Owen, T.W., Carlson, T.N., Gillies, R.R., 1998. An assessment of satellite remotely-sensed land cover parameters in quantitatively describing the climatic effect of urbanization. International Journal of Remote Sensing 19 (9), 1663-1681.

Rosenfeld, A.H., Akbari, H., Bretz, S., Fishman, B.L., Kurn, D.M., Sailor, D., Taha, H., 1995. Mitigation of urban heat islands: materials, utility programs, updates. Energy and Buildings 22, 255-265.

Sailor, D.J., 1998. Simulations of annual degree day impacts of urban vegetative augmentation. Atmospheric Environment 32 (1), 43-52.

Sailor, D.J., 2003. Streamlined Mesoscale Modeling of Air Temperature Impacts of Heat Island Mitigation Strategies. Final Report for US EPA Assistance ID No. 82806701, 28 pp.

Sailor, D.J., Kalkstein, L.S., Wong, E., 2002. The potential of urban heat island mitigation to alleviate heat-related mortality - methodological overview and preliminary modeling results for Philadelphia. In: Fourth Symposium on the Urban Environment. American Meteorological Society, Norfolk VA.

Santamouris, M., Mihalakakou, G., Papanikolaou, N., Asimakopoulos, D.N., 1999. A neural network approach for modeling the heat island phenomenon in urban areas during the summer period. Geophysical Research Letters 26 (3), 337-340.

Taha, H., 2003. Potential Meteorological and Air-quality Implications of Heatisland Reduction Strategies in the Houston-Galveston TX region. LBL Technical Note HIG-12-2002-01. LBL, 143 pp.

Taha, H., Konopacki, S., Akbari, H., 1998. Impacts of lowered urban air temperatures on precursor emission and ozone air quality. Journal of the Air \& Waste Management Association 48 (9), 860-865.

Taha, H., Sailor, D.J., 1997. Modeling the impacts of large-scale albedo changes on ozone air quality in the south coast air basin. Atmospheric Environment 31 (11), 1667-1676.

Tarleton, L.F., Katz, R.W., 1995. Statistical explanation for trends in extreme summer temperatures at Phoenix, Arizona. Journal of Climate 8 (6), $1704-1708$.

Travis, D.J., Meentemeyer, V., Suckling, P., 1987. Influence of meteorological conditions on urban/rural temperature and humidity differences for a small city. Southeastern Geographer 27 (2), 90-100.

Yoshikado, H., Tsuchida, M., Jauregui, E., 1996. High levels of winter air pollution under the influence of the urban heat island along the shore of Tokyo Bay heat island development in Mexico city. Journal of Applied Meteorology $35(10), 1804-1813$. 